\title{
Elective cardiac retransplantation: A viable option that can be repeated
}

\author{
Hannah Copeland, MD, ${ }^{\mathrm{a}}$ Romana Coelho-Anderson, RN, CCTC, ${ }^{\mathrm{b}}$ Nicole Mineburg, RN, CCTC, \\ Michael McCarthy, BS, ${ }^{\mathrm{b}}$ and Jack G. Copeland, MD ${ }^{\mathrm{a}}$
}

Objective: Our hypothesis is that cardiac retransplantation is a viable option for selected recipients. Furthermore, in some patients multiple retransplantations are reasonable.

\begin{abstract}
Methods: We studied 23 patients who had all received an elective second, third, or fourth cardiac transplant over a 25-year period. Comparisons were made with 792 primary transplantations. Subsequent retransplantations (third and fourth time) were elective and included in the evaluation.

Results: Twenty-three patients electively received a second, 4 a third, and 1 a fourth transplant for coronary vasculopathy or chronic graft failure. Sixteen $(70 \%)$ patients were men, and $7(30 \%)$ were women. Median survival in years for primary cardiac recipients was 10.7 years; for a second transplantation, median survival from the date of retransplantation was 9.3 years. Average age at the time of first transplantation was 47.8 years, and it was 44.3 years at the time of second transplantation. No significant difference was noted in Kaplan-Meier survival curves between patients undergoing primary transplantation and elective retransplantation. Survival at 1 year for patients undergoing a first transplantation was $88.8 \%$, and it was $81.8 \%$ for patients undergoing retransplantation. Patient survival at 10 years was nearly identical for patients undergoing first-time transplantation and those undergoing retransplantation (58\%). All 5 third- and fourth-time transplant recipients survived.

Conclusions: Cardiac retransplantation is a reasonable option for elective recipients with coronary vasculopathy or chronic graft failure. Survival for groups undergoing primary transplantation and retransplantation is similar. Careful selection of this small group of cardiac recipients (3\% of the total) might be the key to success. (J Thorac Cardiovasc Surg 2011;141:822-7)
\end{abstract}

Since the first successful cardiac retransplantation in $1974,{ }^{1}$ multiple reports have summarized experiences ${ }^{2-7}$ with adults and children. Nevertheless, the topic has remained controversial for more than 3 decades, but there are some accepted guidelines. Retransplantation is done in only $2 \%$ to $3 \%$ of primary transplant recipients and is reserved for "good" or "selected" patients who undergo transplantation electively at 6 months or more after the first transplantation. Most of these patients have advanced coronary vasculopathy at the time of retransplantation. In this patient group short- and long-term survival has been indistinguishable from that after primary transplantation. ${ }^{2}$

Cardiac recipients with intractable rejection or graft failure in the first days to 6 months after initial transplantation have had much higher mortality rates ${ }^{8}$ with retransplantation. Most authors have discouraged retransplantation in this group.

From the Section of Cardiothoracic Surgery, ${ }^{a}$ University of California San Diego, San Diego, Calif; and University Medical Center, ${ }^{\mathrm{b}}$ Tucson, Ariz.

Disclosures: Authors have nothing to disclose with regard to commercial support.

Read at the 36th Annual Meeting of The Western Thoracic Surgical Association, Ojai, California, June 23-26, 2010.

Received for publication June 14, 2010; revisions received Sept 13, 2010; accepted for publication Nov 14, 2010; available ahead of print Jan 27, 2011.

Address for reprints: Jack Copeland, MD, 200 Arbor Dr, MC 8892, San Diego, CA

92103 (E-mail: jackcope3@gmail.com).

$0022-5223 / \$ 36.00$

Copyright $($ C 2011 by The American Association for Thoracic Surgery doi:10.1016/j.jtcvs.2010.11.027
Of historical interest, the first successful cardiac retransplantation was in a 13-year-old with intractable rejection of his first transplanted heart. ${ }^{1}$ He was unstable for nearly 60 days before having a second transplantation, followed by survival for more than 10 years. This was in the era of prednisone, azathioprine, and rabbit antithymocyte globulin therapy.

We report our experience with retransplantation since 1981.

\section{MATERIALS AND METHODS}

We received human subject institutional review board approval for a retrospective chart review. A waiver of consent was also approved for the conduct of this study. Chart reviews of the patients undergoing retransplantation documented demographic and etiologic information, as well as the patient's condition, hemodynamics, reason for retransplantation, and complications, including infection, rejection, and end-organ failure. One-year evaluation studies, complications of patients undergoing multiple retransplantation, and survival durations after second, third, and fourth transplantations were also recorded. All primary cardiac transplant recipients at our institution served as the control group for Kaplan-Meier curves. Retransplantation survival curves included all retransplantations (ie, first through third). Tests for equality of these curves were performed with the log-rank test. Time to event analyses included comparisons of patients undergoing primary transplantation versus patients undergoing retransplantation for patient survival, graft survival, rejection, renal failure, and leukopenia. Patients who received a third transplant and the patient who received a fourth transplant were included in these analyses. Immunosuppresion changed over the course of this experience from reliance on cyclosporine and azathioprine in addition to steroid to more use of tacrolimus and mycophenylate mofetil and steroids. We did not have a special protocol in these patients. All patients undergoing 
transplantation are treated with prophylactic statin therapy. We did not switch to sirolimus in an attempt to prevent graft coronary vasculopathy. Recently, all of our patients have had baseline coronary arteriographic and intravascular ultrasound studies at 3 months and were then followed yearly for the first 4 to 5 years; thus we did not have a special follow-up protocol in place for patients undergoing retransplantation.

Retransplant recipient selection was similar to initial selection. Patients were excluded for obesity (body mass index, $\geq 35 \mathrm{~kg} / \mathrm{m}^{2}$ ), chronic renal insufficiency (creatinine, $>1.5 \mathrm{mg} / \mathrm{dL}$; glomerular filtration rate, $<35 \mathrm{~mL} /$ $\mathrm{min}$ ), a history of noncompliance, any substance abuse or smoking, any life-threatening systemic disease, and poor general condition.

Listing for retransplantation was done exactly as it was for patients undergoing primary transplantation. Once listed, the probability of transplantation was not different from that of the primary transplant candidates. The time on the waiting list thus was a function of accumulated waiting time, blood type, and United Network for Organ Sharing status. Twelve of these patients were status IB receiving inotropic support, 9 were waiting for their first retransplantation (second transplantation), and 3 were waiting for their second retransplantation (third transplantation). Waiting times have changed over the past 25 years, but in general, patients with blood types $\mathrm{O}$ and $\mathrm{A}$ in United Network for Organ Sharing status IB have waited for 4 months to 1 year, and those in status II have waited for more than 1 year. Those with blood types $\mathrm{B}$ and $\mathrm{AB}$ have had shorter waiting times. Our patients followed the same trends. Donor selection was no different than for primary transplant recipients.

\section{RESULTS}

From March 1979 to September 2009, we performed 844 cardiac transplantations. Twenty-six $(3 \%)$ were retransplantations. Three patients receiving a second transplant were not included in our evaluation because they were emergency, total artificial heart, bridge to transplantation patients followed by emergency second transplantations. These 3 patients did not follow the standard evaluation, listing, and protocol before their retransplantation and thus were excluded from our study. One of those survived 9 years, and the other 2 died in less than 30 days.

We have evaluated 23 consecutive patients who had a total of 51 transplantations: 23 primary transplantations, $23 \mathrm{sec}-$ ond transplantations, 4 third transplantations, and 1 fourth transplantation. Our first cardiac retransplantation was done in 1984. All retransplant recipients in this report, with one exception, had elective procedures. That exception was a patient who, at another institution, received his second transplant on an emergency basis 5 days after the first and then, 4 years later, received a third transplant electively at our center. There were 16 male and 7 female patients ranging in age at the time of second transplantation from 8 to 64 years (mean, $42.4 \pm$ 15.9 years), including 4 pediatric patients who were aged 8 to 18 years. Eighteen were white, 4 were Hispanic, and 1 was Asian. Blood groups were as follows: A, 15 patients; $\mathrm{O}, 4$ patients; $\mathrm{B}, 3$ patients; and $\mathrm{AB}, 1$ patient. Primary causes that resulted in heart failure and the initial transplantation included 9 ischemic, 7 dilated, 3 congenital, 3 peripartum, and 1 congenital. Before the initial heart transplantation, transpulmonary gradients mean values were less than $12 \mathrm{~mm} \mathrm{Hg}$, and pulmonary vascular resistance was less than 3 Wood units. Fourteen had positive cytomegaloviral serologies.
Indications for second transplantation included coronary vasculopathy in 21 patients, restrictive cardiomyopathy in 1 patient, and chronic graft failure in 1 patient. There was 1 patient who underwent retransplantation at another hospital at 5 days. The remainder all underwent retransplantation at our center from 1.92 to 10.4 years after the primary transplantation (mean, $5.8 \pm 4$ years; median, 4.5 years). Preretransplantation hemodynamics were generally those of patients with deterioration after the first transplantation from diffuse coronary vasculopathy. Twelve were receiving inotropic support with dobutamine $(n=9)$, milrinone $(n=2)$, and norepinephrine $(\mathrm{n}=1)$. Five were diabetic. On preretransplantation catheterization, mean pressures were as follows: right atrium, $10 \mathrm{~mm} \mathrm{Hg}$; pulmonary artery, 30/20 mm Hg; pulmonary artery wedge pressure, $18 \mathrm{~mm} \mathrm{Hg}$; and cardiac output, 4.0 L/min. Left ventricular ejection fraction determined by means of echocardiography averaged 32\%. New York Heart Association functional class averaged 3.0.

On 1-year follow-up coronary angiograms after the second transplantation, only 1 patient had any coronary disease pathology. This was a thrombotic occlusion of the left anterior descending artery secondary to the catheterization that resolved with stenting but did cause a nonfatal myocardial infarction, and the patient died about 1 month later. Left ventricular ejection fractions were also normal, with a mean value of $59 \% \pm 7 \%$. Survival after the second transplantation ranged from 2.5 months to 23 years (mean, $5.6 \pm 5.6$ years; median, 5.5 years). During that period of 128 patient-years, there were 21 treated infections ( 0.16 per patient-year). All but 1 patient was taking tacrolimus. Seven were taking mycophenylate, with the remainder taking azathioprine, and all were receiving low-dose prednisone.

Four patients had third transplantations 2.8 to 11.5 years after the second transplantation (mean, $5.9 \pm 3.9$ years). Indications included severe coronary vasculopathy $(\mathrm{n}=3)$ and heart failure $(\mathrm{n}=1)$ after an episode of acute rejection. They have survived for a mean duration of $9 \pm 1.6$ years (range, 3.8-11.5 years) after the third transplantation. Three of the four patients died: 1 died from coronary vasculopathy, 1 experienced sudden death, and 1 died from pulmonary varicella. The fourth of these patients had a fourth transplantation for severe coronary vasculopathy 10.5 years after his third transplantation. He remains alive and in New York Heart Association functional class I and is currently on dialysis. He is 5.5 years after the fourth transplantation and 23.7 years after his first transplantation at age 11 years. $\mathrm{He}$ is being evaluated for a kidney transplantation.

Thus far, the mean survival time of all retransplant recipients has been $13.6 \pm 6$ years (range, 2.6-24.9 years). Nine $(39 \%)$ of the patients are still surviving at 3.6 to 24.9 years (mean, $17.3 \pm 7.6$ years) after the initial transplantation. The median survival has been 9.3 years (Figure 1), and the Kaplan-Meier survival curves comparing our primary transplantation group with the retransplantation group are not 


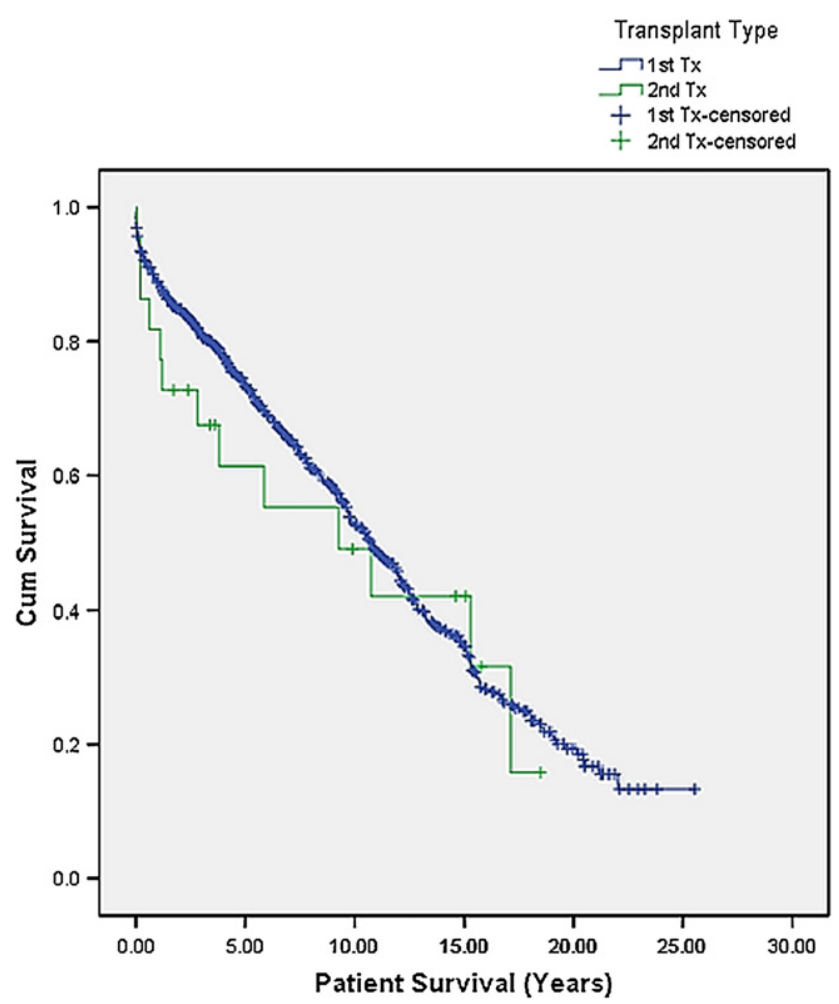

FIGURE 1. Patient survival: 818 patients undergoing primary transplantation are shown in blue, and 23 patients undergoing elective retransplantation are shown in green. Tx, Transplantation.

significantly different (Figure $1 ; P=.61, \log$-rank test). Table 1 summarizes the currently living patients with respect to total survival, number of transplantations, coronary anatomy studies (all but 1 have had recent angiographic and intravascular ultrasound studies), hemodynamic data, and echocardiographic left ventricular ejection fraction.

Rejection was significantly less in the primary transplantation group, with a freedom from rejection at 1 year after transplantation of $46 \%$ compared with the retransplantation group's freedom from rejection of $18 \%(P=.02, \log$-rank test; Figure 2).

Renal dysfunction, defined as a serum creatinine level of greater than $2.25 \mathrm{mg} / \mathrm{dL}$, was significantly more common in the retransplantation group. At 1 and 5 years after transplantation, freedom from renal dysfunction was $69 \%(n=510)$ and $50 \%(\mathrm{n}=255)$ for primary recipients and $49 \%$ $(\mathrm{n}=10)$ and $30 \%(\mathrm{n}=4)$ for retransplant recipients, respectively. Kaplan-Meier curves for freedom from renal dysfunction (Figure 3) demonstrated significantly less renal failure in the primary transplantation group than in the retransplantation group $(P=.03, \log$-rank test).

White blood cell counts over the years were also lower for the retransplant recipients. We defined leukopenia as any white blood cell count of less than $3500 / \mathrm{mL}$. The primary recipients had significantly fewer leukopenic episodes than the retransplant recipients $(P=.02, \log$-rank test) (Figure 4).

Fourteen patients have died at 0.04 to 16 years after retransplantation, including 3 having undergone 3 transplantations (Table 2). Total survival in these patients ranged from 2.59 to 24.75 years (mean, 11.3 years). Causes of death are shown in Table 2 and include 5 episodes of sudden death (1 confirmed secondary to coronary vasculopathy and 1 iatrogenic), 4 infections, 2 strokes, and 1 case each of lung cancer, multiple organ failure, and renal failure. Four patients died within 6 months of retransplantation: 3 from infection and 1 from multiple organ failure. Of the remaining 10 deaths, 5 were sudden, 2 were strokes, 1 was from cancer, 1 was from renal failure, and 1 was from viral pneumonia.

\section{DISCUSSION}

The 2010 International Society for Heart \& Lung Transplantation Registry reports ${ }^{9}$ the following causes of death

TABLE 1. Current survivors showing total time of survival, number of transplants, and time since the second, third, and fourth transplantations

\begin{tabular}{|c|c|c|c|c|c|c|c|c|c|}
\hline $\begin{array}{c}\text { Patient } \\
\text { no. } \\
\end{array}$ & $\begin{array}{c}\text { Total } \\
\text { survival }(\mathbf{y}) \\
\end{array}$ & $\begin{array}{c}\text { No. of } \\
\text { transplantations } \\
\end{array}$ & $\begin{array}{c}\text { Years since second, } \\
\text { third, and fourth } \\
\text { transplantations }\end{array}$ & $\begin{array}{c}\text { Coronary } \\
\text { arteries }\end{array}$ & IVUS & $\begin{array}{c}\text { RA } \\
(\mathbf{m m} \mathbf{H g})\end{array}$ & $\begin{array}{c}\text { PA } \\
(\mathrm{mm} \mathrm{Hg})\end{array}$ & $\begin{array}{c}\text { PAW } \\
(\mathrm{mm} \mathrm{Hg})\end{array}$ & $\begin{array}{c}\text { LVEF by } \\
\text { echocardiography }\end{array}$ \\
\hline 1 & 3.66 & 2 & 2.16 & Normal & $1 \mathrm{~mm}$ LAD & 12 & $35 / 20$ & 5 & 44 \\
\hline 2 & 8.75 & 2 & 2.83 & Normal & Normal & 2 & $18 / 8$ & 6 & 60 \\
\hline 3 & 13.3 & 2 & 4 & Normal & $0.5 \mathrm{~mm}$ LAD & 12 & $47 / 22$ & 24 & 65 \\
\hline 4 & 14.66 & 2 & 3.83 & Normal & $0.5 \mathrm{~mm}$ LAD & 7 & $38 / 18$ & 18 & 55 \\
\hline 5 & 20.16 & 2 & 15.08 & Normal & $1 \mathrm{~mm}$ LAD & 14 & $40 / 24$ & 20 & 45 \\
\hline 6 & 22.5 & 2 & 16.7 & Normal & $1-1.5 \mathrm{~mm}$ LAD & & $28 / 16$ & 8 & 65 \\
\hline 7 & 23.7 & 2 & 10.25 & Normal & Normal & 5 & $16 / 10$ & 9 & 70 \\
\hline 8 & 23.7 & 4 & $2.75,10.5,5.5$ & Normal & Normal & 4 & $20 / 12$ & 6 & 55 \\
\hline 9 & 24.9 & 2 & 23 & $\begin{array}{l}\text { Normal } \\
\qquad(>10 \mathrm{y} \text { ago })\end{array}$ & $\begin{array}{l}1 \text { mm LAD } \\
\quad(>10 \text { y ago })\end{array}$ & 4 & $19 / 12$ & 10 & 78 \\
\hline
\end{tabular}

All catheterizations except for patient 9 (performed in 1989) and patient 7 (performed in 2005), were completed in the past 2 years. Coronary arteries, Angiographic assessment of coronary artery anatomy; IVUS, intravascular ultrasound standard to examine mid-left anterior descending coronary artery for subintimal thickening; $R A$, right atrium; $P A$, pulmonary artery; $P A W$, pulmonary artery wedge pressure; $L V E F$, left ventricular ejection fraction; $L A D$, left anterior descending coronary artery. 


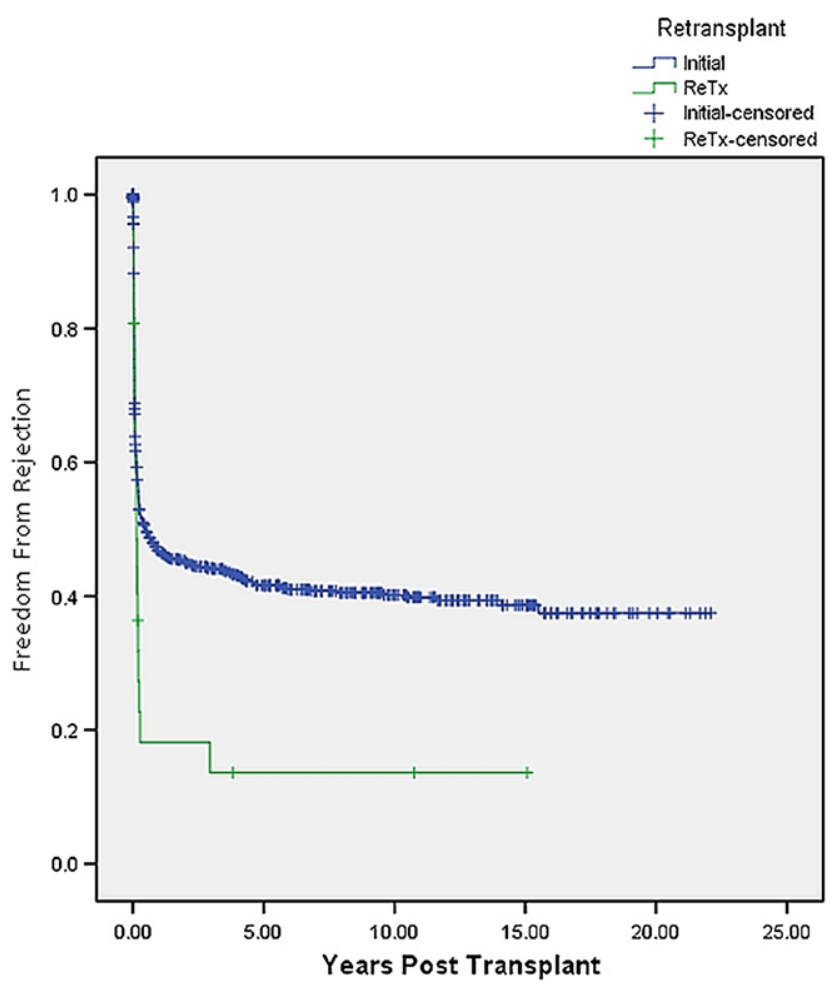

FIGURE 2. Freedom from rejection: patients undergoing primary transplantation are shown in blue, and patients undergoing retransplantation are shown in green. Tx, Transplantation; ReTx, retransplantation.

for patients undergoing primary transplantation as percentages of total deaths for recipients surviving for more than 10 years: coronary vasculopathy, $14 \%$; infection, $9.8 \%$; cerebrovascular, $4.5 \%$; and malignancy, $18 \%$.

In a recent single-center review of cardiac retransplantation, ${ }^{3}$ postretransplantation survival was found to be significantly lower than in primary transplant recipients. From the same institution, a follow-up study found a higher incidence of comorbidities in retransplant recipients. ${ }^{9}$ Among their 23 deaths, $34 \%$ were from malignancy, $26 \%$ were from infection, $13 \%$ were from rejection, $17 \%$ were from sudden death or coronary vasculopathy, and $4 \%$ were from postoperative bleeding. The predominant causes in their series and in ours were infection and coronary vasculopathy/sudden death. They saw more malignancy.

Our experience points to 2 types of postretransplantation deaths: those that occurred at less than 6 months related to infection $(n=3)$ and multiple organ failure $(n=1)$ and those that occurred later related to coronary vasculopathy $(\mathrm{n}=4)$ and chronic posttransplantation issues $(\mathrm{n}=6)$. Two of the sudden deaths were at just over a year after retransplantation, and the other 3 sudden deaths were more than 5 years after retransplantation. The other causes of late death (ie, stroke, renal failure, cancer, and opportunistic infection) are also predictable causes of late mortality in a primary transplantation population.

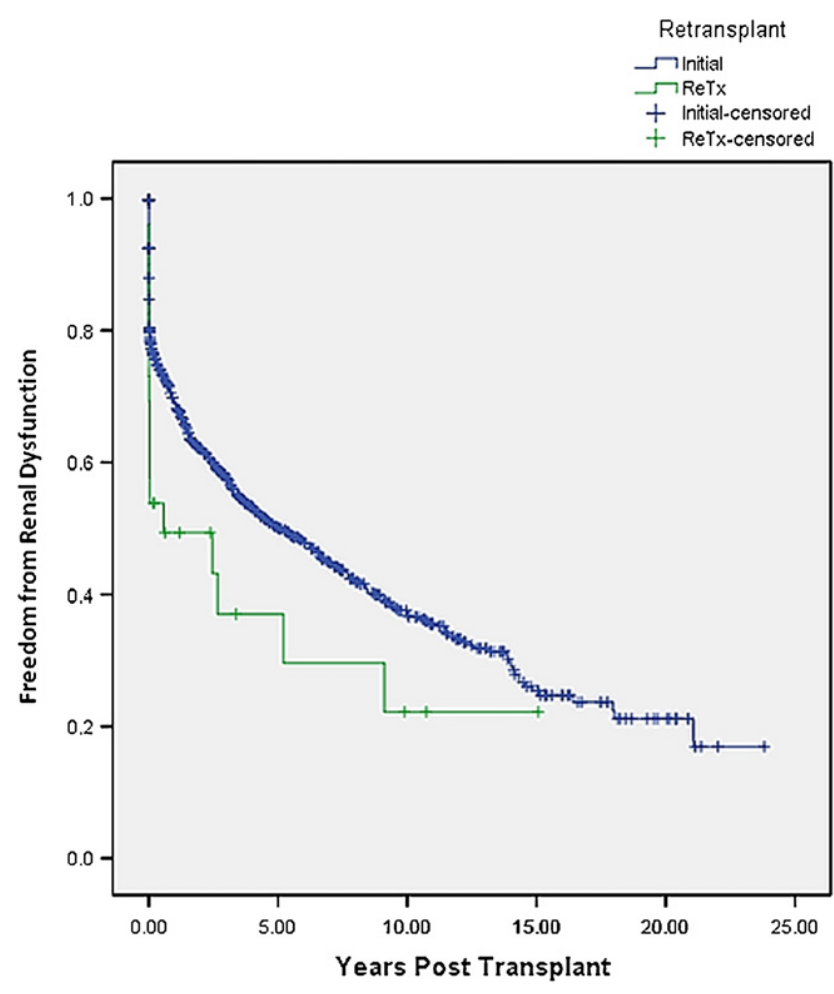

FIGURE 3. Freedom from serum creatinine level of greater than $2.25 \mathrm{ml} /$ $\mathrm{dL}$ for primary transplant recipients (blue) and retransplant recipients (green). Tx, Transplantation; ReTx, retransplantation.

Nearly all patients selected for retransplantation had severe coronary vasculopathy, but the incidence of coronary vasculopathy after retransplantation was not as impressive as expected. Sudden death, a presumed manifestation of coronary vasculopathy, did cause $36 \%$ of the deaths. One of these was iatrogenic, and only 1 was proved coronary vasculopathy. Given the preponderance of coronary vasculopathy before retransplantation, we would have expected more after transplantation. This is particularly true when we look at Table 1, which shows that in the 9 surviving patients there was no epicardial vessel disease and no critical coronary disease as defined by intravascular ultrasound late after retransplantation. Also, the 1-year coronary angiograms after retransplantation did not find significant coronary vasculopathy in any of our patients. One patient had iatrogenic disease and left anterior descending coronary artery dissection from catheterization followed by stenting and died suddenly about 1 month later. The second sudden death at just over 1 year was in the patient who did not have a coronary angiogram. Sudden death and graft coronary disease might not be as strong as we thought.

There were no deaths from rejection. Our approach has been to perform retransplantation in chronically immunosuppressed patients and not escalate therapy. We have attempted after the first 1 to 2 weeks to return all of these patients to the same level of immunosuppresion they were 
TABLE 2. Nonsurvivors showing total years of survival after first transplantation, number of transplantations, times of survival after the second and third transplantations, and causes of death

\begin{tabular}{lcccl}
\hline Patient no. & $\begin{array}{c}\text { Total survival } \\
\text { time (y) }\end{array}$ & $\begin{array}{c}\text { No. of } \\
\text { transplantations }\end{array}$ & $\begin{array}{c}\text { Survival after second and } \\
\text { third transplantation }(\mathbf{y})\end{array}$ & \multicolumn{1}{c}{ Cause of death } \\
\hline 1 & 2.59 & 2 & 0.17 & Aspergillus species-induced pneumonia \\
2 & 4.42 & 2 & 1.17 & Sudden \\
3 & 5 & 2 & 0.5 & Sepsis \\
4 & 6.72 & 2 & 0.04 & Multiorgan failure \\
5 & 7.61 & 2 & 0.19 & Mediastinitis \\
6 & 8.08 & 2 & 5.75 & Sudden \\
7 & 8.75 & 2 & 2.83 & Stroke \\
8 & 12.5 & 2 & 9.25 & Lung cancer \\
9 & 13 & 2 & 10.75 & Cerebral hemorrhage \\
10 & 14.34 & 2 & 3.92 & Renal failure \\
11 & 15 & 3 & $3.38,11.5$ & Sudden \\
12 & 17.16 & 2 & 1.16 & Sudden iatrogenic coronary disease \\
13 & 18.42 & 3 & $11.5,3.75$ & Varicella pneumonia \\
14 & 24.75 & 3 & $10.5,5.5$ & Coronary vasculopathy \\
\hline
\end{tabular}

There were 5 sudden deaths, 4 presumed to be from coronary vasculopathy. One of these was confirmed by postmortem examination.

receiving before retransplantation. There was a tendency for crossover to mycophenalate and tacrolimus. Only 1 of these patients was started on sirolimus, and that was for decreased renal function. Our finding that rejection in this retransplantation group was increased raises questions regarding optimal immunosuppresion. We have not changed our approach of lower-level immunosuppresion in retransplantation from what would be used in primary transplantations because we have seen no fatal rejections, and we believe we might have avoided the previously reported higher incidences of infection and malignancy. ${ }^{9}$

The mean survival for our retransplant recipients was 13.6 years for the entire group and 17.3 years for the current survivors. Both of these numbers compare favorably with the International Society for Heart \& Lung Transplantation Registry. The 4 patients receiving a third transplant had additional survival of 3.8 to 11.5 years, and 1 patient had a fourth transplant 10.5 years after his third transplantation and is still alive 5.5 years after the fourth transplantation and 23.7 years since the first transplantation. We think this experience supports the concept of multiple transplantations. Similar patient survival curves (Figure 1) for patients undergoing primary transplantation and retransplantation also suggest that retransplantation is a viable option. Years of life are gained, and donor hearts are not wasted.

Comparisons of complications for rejection, renal dysfunction, and leukopenia were unfavorable for retransplant recipients. Freedom from rejection at 1 year after transplantation was $46 \%$ for patients undergoing primary transplantation and $18 \%$ for patients undergoing retransplantation. Class III renal dysfunction (serum creatinine, $>2.25 \mathrm{mg} / \mathrm{dL}$ ) was significantly less in the patients undergoing primary transplantations, as was leukopenia (white blood cell count, $<3500 / \mathrm{mL}$ ). Yet in the face of more rejection episodes, more renal dysfunction, and lower white blood cell counts, the retransplant recipients did not have lower probability of survival.

We believe, on the basis of this experience, that in stable selected cardiac recipients, retransplantation is reasonable. Our approach is to evaluate patients for retransplantation using the same criteria we would use for primary recipients.

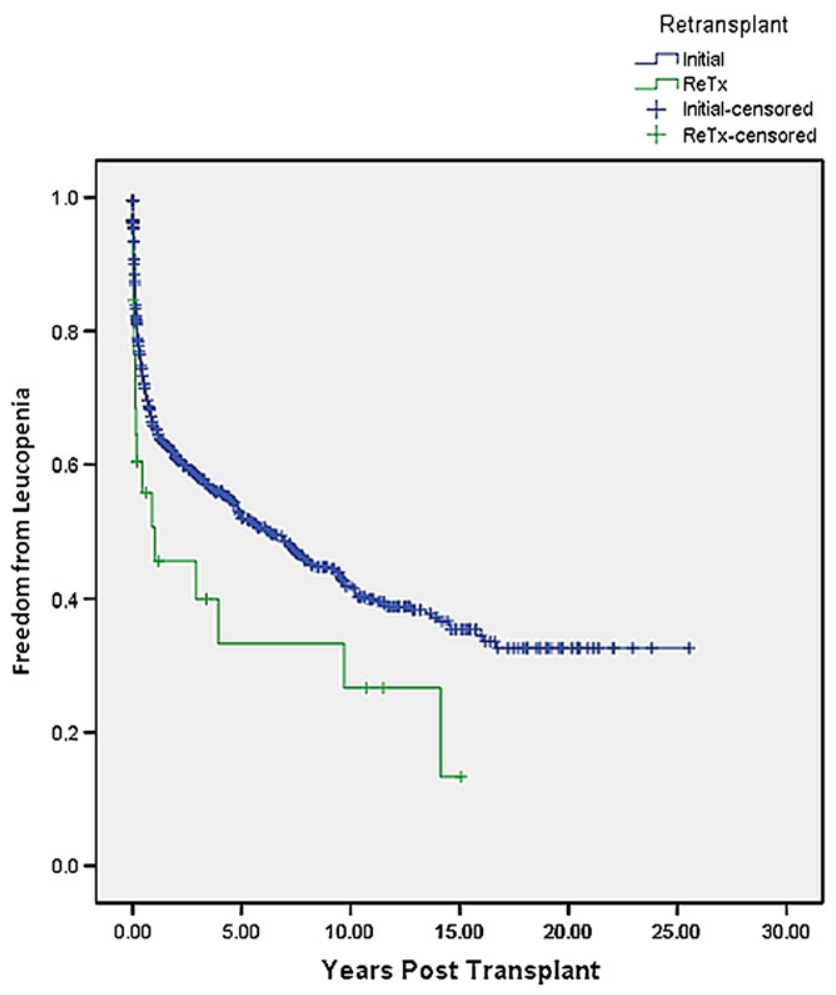

FIGURE 4. Freedom from leukopenia ( $<3500$ white blood cells $/ \mathrm{mL}$ ) for primary transplant recipients (blue) and retransplant recipients (green). $T x$, Transplantation; ReTx, retransplantation. 
Excluding patients who have become high risk requires a stringent application of basic principles of selection. We have avoided patients with morbid obesity, end-organ dysfunction, substance abuse, smoking, poor compliance, life-threatening systemic disease, and poor general condition. Finally, as a result of poor outcomes, we have avoided emergency retransplantation shortly after total artificial heart implantation for the past 20 years.

We were surprised that survival in these "stable retransplant recipients" was not different than in primary patients in our institution, even though the incidences of rejection, renal dysfunction, and leukopenia were higher. Also, for a group who had coronary vasculopathy as the primary reason for retransplantation, the incidence of proved coronary vasculopathy was less than expected.

If one accepts that the retransplantations were indicated and reasonably timed in this retrospective review of 23 cases, then the result has been to add years to a patient's life. An average of 5.6 years of survival per patient was added by the second transplantations and 9.2 patient survival years by the third transplantations. The only fourth transplant recipient has thus far lived an additional 5.5 years. These numbers support a recommendation for performing retransplantation in carefully selected cardiac transplant recipients.

\section{References}

1. Copeland JG, Griepp RB, Bieber CP, Billingham M, Schroeder JS, Hunt S, et al. Successful retransplantation of the human heart. J Thorac Cardiovasc Surg. 1977; 73:242-7.

2. Radovancevic B, McGiffin DC, Kobashigawa J, Cintron GB, Mullen GM, Pitts DE, et al. Retransplantation in 7,290 primary transplant patients: a 10 year multi-institutional study. J Heart Lung Transplant. 2003;22:862-8.

3. Topkara VK, Dang NC, John R, Cheema FH, Barbato R, Cavallo M, et al. A decade experience of cardiac retransplantation in adult recipients. J Heart Lung Transplant. 2005;24:1745-50.

4. John R, Chen JM, Weinberg A, Oz MC, Mancini D, Itescu S, et al. Long-term survival after cardiac retransplantation: a twenty-year single center experience. J Thorac Cardiovasc Surg. 1999;117:543-55.

5. Schnetzler B, Pavie A, Dorent R, Camproux AC, Leger P, Delcourt A, et al. Heart retransplantation: a 23-year single center clinical experience. Ann Thorac Surg. 1998;65:978-83.

6. Kanter KR, Vincent RN, Berg AM, Mahle WT, Forbess JM, Kirshbom PM. Cardiac retransplantation in children. Ann Thorac Surg. 2004;78:644-9.

7. Razzouk AJ, Chinnock RE, Dearani JA, Gundry SR, Bailey LL. Cardiac retransplantation for graft vasculopathy in children. Arch Surg. 1998;133:881-5.

8. ISHLT Registry Online. Available at: http://www.ishlt.org/registries/heartLungRegistry.asp. Accessed June 2010.

9. Tsao L, Uriel N, Leitz K, Naka Y, Mancini D. Higher rate of comorbidities after cardiac retransplantation contributes to decreased survival. J Heart Lung Transplant. 2009;28:1072-4. 